1 Fundação Oswaldo Cruz (Fiocruz), Escola Politécnica de Saúde Joaquim Venâncio (EPSJV) - Rio de Janeiro (RJ), Brasil.

monicavi@fiocruz.br

2 Fundação Oswaldo Cruz (Fiocruz), Escola Politécnica de Saúde Joaquim Venâncio (EPSJV)

- Rio de Janeiro (RJ), Brasil. pina@fiocruz.br

3 Escola de Saúde Pública do Estado de Minas Gerais (ESP-MG) - Belo Horizonte (MG), Brasil.

luciana.davila@esp.mg.gov.br

4 Escola Técnica do SUS

Professora Ena de Araújo

Galvão (ETSUS) - Campo

Grande (MS), Brasil.

nursedenis@yahoo.com.br

5 Secretaria Municipal de Saúde de Blumenau, ESF

Martin Volles I - Blumenau (SC), Brasil.

tutorananci@gmail.com

\section{Trajetórias educacionais e ocupacionais de trabalhadores do Sistema Único de Saúde, e suas expectativas profissionais}

\author{
Educational and occupational trajectories of workers of the Unified \\ Health System and their professional expectations
}

Monica Vieira', Filippina Chinelli2 ${ }^{2}$ Luciana Souza d'Ávila ${ }^{\mathbf{3}}$, Denise Rodrigues Fortes ${ }^{\mathbf{4}}$, Nancí

Aparecida da Silva David $\mathbf{5}$

RESUMO Este artigo discute a relação entre as trajetórias educacionais e ocupacionais e as expectativas de trabalhadores do Sistema Único de Saúde no Brasil. É parte de uma pesquisa que recuperou essas trajetórias com base em entrevistas realizadas com trabalhadores técnicos de quatro grupos ocupacionais. A análise das entrevistas permitiu constatar que a inserção na área da saúde é vivenciada como menos errática quando comparada às trajetórias anteriores destes trabalhadores, especialmente para aqueles que experimentaram incertezas advindas de inserções instáveis e precárias. Entre os grupos estudados, os da enfermagem, sobretudo, são os que vêm construindo suas expectativas profissionais na mesma área de atuação.

PALAVRAS-CHAVE Desenvolvimento de pessoal. Categorias de trabalhadores. Pessoal de saúde.

ABSTRACT This article discusses the relationship between educational and occupational trajectories and the expectations of the Unified Health System workers in Brazil. It is part of a research that recovered these trajectories based on interviews with technical workers from four occupational groups. The analysis of the interviews found that the insertion in the health area is experienced as less erratic when compared to the previous trajectories of these workers, especially for those who experienced uncertainties arising from unstable and precarious insertions. Among the groups studied, those of nursing, mainly, are those who have been building their professional expectations in the same practice field.

KEYWORDS Staff development. Occupational groups. Health personnel. 


\section{Introdução}

Este artigo analisa a relação entre as trajetórias e expectativas de futuro de trabalhadores do Sistema Único de Saúde (SUS) no Brasil, considerando o contexto de mudanças que vem afetando a organização e a gestão do trabalho na saúde, sobretudo a partir dos anos 2000. Nesse período, conforme aponta a literatura pertinente, o crescimento dos postos de trabalho impulsionado pela ampliação da atenção básica como política publica de saúde prioritária no País é acompanhado pelo aumento da escolaridade e da qualificação profissional dos trabalhadores. Verificam-se, contudo, o descompasso frequente entre formação e inserção no mercado de trabalho setorial (FRANCISCO, 2015; VIEIRA ET AL., 2013), e uma intensificação das parcerias público-privadas e de vínculos de trabalho precarizados.

Nesse contexto, a área da saúde passa a experimentar, também, o desencontro entre trajetórias ocupacionais e expectativas de realização profissional, sobretudo entre trabalhadores técnicos. Castro (2006), ao analisar a transição de jovens entre escola e trabalho, diante das condições atuais do mercado de trabalho, aponta as várias e diferenciadas experiências que marcam as trajetórias ocupacionais contemporâneas. Isto configura um processo, que se verifica, cada vez mais, na inserção ocupacional dos trabalhadores como um todo.

Todavia, as mudanças recentes na estrutura dos mercados de trabalho, em especial, nos grandes mercados metropolitanos, pareceram estender a parcelas ponderáveis da população ativa um traço que considerávamos como 'juvenil'. Fragilização dos vínculos e intensificação das transições ocupacionais tornaram-se moedas correntes, num contexto marcado pelo aumento dos patamares de desemprego, pela ampliação do tempo de procura de trabalho e pela recorrência na desocupação. (CASTRO, 2006, P. 172)
Essas observações remetem ao fato de que, nas sociedades contemporâneas, na medida em que a demanda por segurança social - incluindo-se o emprego -

tem-se mostrado ilimitada, [...] a capacidade dos sistemas de proteção social em supri-la apresenta limites que variam conforme cada contexto social específico. (SILVA, 2011, P. 202).

Diante disto, este artigo procura explicitar a transição de trajetórias incertas e inseguras para outro momento da vida desses trabalhadores, no qual que se ampliam as possibilidades de construção de projetos de qualificação, trabalho e vida. Por projeto, entendemos, de acordo com Velho (2003, P. 40) - baseado em Schutz (1979) -, "a conduta organizada para atingir finalidades específicas" no interior de um "campo de possibilidades", "dimensão sociocultural, espaço para a formulação e implementação de projetos".

Para tanto, o texto inicialmente apresenta, de forma breve, as concepções de trajetórias e expectativas, seguindo-se a explicitação dos procedimentos metodológicos utilizados. A terceira parte trata de caracterizar os trabalhadores técnicos entrevistados. Finalmente, os resultados obtidos são apresentados a partir de três eixos, que permitem apreender como os trabalhadores constroem suas expectativas de futuro: insuficiência da formação técnica; (im) permanência na ocupação; e, em outra etapa da vida, é possível recomeçar.

\section{Trajetórias e expectativas}

As trajetórias ocupacionais remetem à construção processual de percursos no mercado de trabalho (SILVA, 2011; CASTRO, 2006). A pesquisa na qual se baseia este texto permite acrescentar que os percursos educacionais também constituem uma dimensão importante e articulada de análise das trajetórias. Esta perspectiva procura ultrapassar interpretações que considerem apenas os indivíduos, 
visto que, conforme ressalta Silva (2011, P. 207), pode-se incorrer no entendimento da individualização como atomização, o que

reforça o entendimento de que não existem mais padrões de trajetórias compartilhadas coletivamente por trabalhadores situados numa mesma categoria, seja ela ocupacional, de sexo, de faixa etária, de escolaridade, de remuneração e assim por diante. (SILVA, 2011, P. 207).

Ainda que as expectativas de futuro sejam marcadas pela atual configuração do mundo do trabalho, considera-se necessário agregar a essa perspectiva o fato de que elas também se diferenciam por aspectos que vão além da posição ocupacional na estrutura social, devendo-se considerar que as experiências de vida dos sujeitos ultrapassam a família e abrangem as múltiplas vivências, complexas e contraditórias, relacionadas a outros espaços de sociabilidade. Nogueira (2012, P. 28), com base em Lahire (2006), afirma, a respeito disto, que

a experiência de vida de um ator particular dificilmente pode ser deduzida de seu pertencimento a uma única coletividade ou do fato de estar inserido numa posição específica da estrutura social. A subjetividade de cada indivíduo ou, mais especificamente, o quadro de disposições que o orienta seria, assim, algo complexo ou mesmo contraditório, algo formado a partir de experiências múltiplas vividas nos mais diferentes contextos sociais. É de se esperar que haja diferenças significativas de comportamento entre grupos sociais e mesmo entre indivíduos de um mesmo grupo social.

Portanto, é possível inferir que existem regularidades e diferenças entre os percursos de trabalhadores do mesmo grupo ocupacional, considerando as distintas inserções laborais, as qualificações profissionais, os ciclos de vida. Acrescente-se que tendem a configurar trajetórias orientadas no sentido da construção de suas profissionalidades, entendendo-se que o termo engloba não só a profissão, mas também os aspectos ideológicos, culturais, históricos e econômicos sociais referidos a um determinado campo profissional.

A análise das expectativas de futuro deve considerar o que se denomina como campo de possibilidades, o que significa privilegiar a inserção social dos trabalhadores, que torna factível a construção de um projeto de vida. Essa perspectiva permite articular as condições materiais e a dimensão subjetiva que informam a construção das trajetórias educacionais e ocupacionais dos entrevistados. Como também afirma Alves $(2008$, P. 2),

$\mathrm{Na}$ verdade, trata-se de apreender, por meio das narrativas pessoais de trabalho e vida de homens e mulheres assalariados, um dos elementos compositivos inelimináveis da experiência vivida e percebida dos sujeitos humanos, isto é, seus sonhos, expectativas e aspirações de vida e trabalho sob as condições da nova precariedade salarial.

Ressalte-se que a subjetividade é tomada como uma construção histórico-social, procurando-se, portanto, ultrapassar a noção individualizante e concebê-la, obrigatoriamente, na relação subjetividade-intersubjetividade (SAVIANI, 2004). Isto é,

o indivíduo só pode se constituir como homem e, nessa condição, como sujeito de seus próprios atos, nas relações cotidianas com os outros homens. [...] em Marx a questão da subjetividade se manifesta como indissociável da intersubjetividade. (SAVIANI, 2004, P. 13).

\section{Procedimentos metodológicos}

A pesquisa da qual este artigo deriva contou com a participação de profissionais de cinco escolas técnicas do SUS, das cinco macrorregiões brasileiras, o que permitiu a realização de 130 entrevistas, com média de uma hora de duração cada, número suficiente, 
considerado o critério de saturação das informações. As entrevistas foram orientadas por roteiros que contemplaram, de forma geral, os seguintes aspectos: caracterização socioeconômica, composição familiar, trajetória educacional, trajetória ocupacional com ênfase na inserção no mercado de trabalho em saúde, relação entre formação e ocupação, motivação de ingresso e permanência na área, e expectativas profissionais.

Foram realizadas 30 entrevistas no Rio de Janeiro (RJ) e 20 nos demais municípios: Belo Horizonte (MG), Campo Grande (MS), Salvador (BA), Blumenau (SC) e Rio Branco (AC), nos anos de 2013 e 2014, distribuídas de forma equilibrada entre trabalhadores dos quatro grupos selecionados e que ocupavam postos de nível médio ligados à atenção básica, a saber: auxiliares e técnicos de enfermagem, agentes comunitários de saúde, auxiliares e técnicos de saúde bucal e agentes de vigilância em saúde (epidemiológica, sanitária e ambiental).

Os trabalhadores foram convidados a partir da rede de relações dos pesquisadores, com o intuito de diversificá-los quanto a: grupo ocupacional, idade, gênero, tipo de vínculo, nível de qualificação e tempo de permanência no trabalho em saúde. As entrevistas foram realizadas nos lugares e momentos de conveniência dos entrevistados, tendo ocorrido, sobretudo, nos seus locais de trabalho, respeitando os intervalos de suas rotinas laborais. O projeto foi aprovado por Comitê de Ética em Pesquisa com Seres Humanos da Escola Politécnica de Saúde Joaquim Venâncio/Fundação Oswaldo Cruz (Fiocruz), sob o Certificado de Apresentação para Apreciação Ética (CAAE) $n^{0}$ 0062.0.408.000-11, Protocolo no 201L/0176.

Todas as entrevistas gravadas e transcritas foram analisadas mediante a análise de conteúdo (MINAYO, 2004), com base em uma perspectiva compreensiva que busca os sentidos e os significados da fala dos trabalhadores, entendida como resultante de condições históricas e sociais, assim como a interpretação elaborada pelos pesquisadores. A análise realizada possibilitou a construção de sínteses de cada entrevista e a identificação de temas centrais para a compreensão das trajetórias educacionais e ocupacionais, como escolaridade e ocupação dos pais; a construção da relação entre escola e trabalho; as motivações para a inserção na área da saúde e as expectativas profissionais. Como este texto se detém em um desses temas - as expectativas - procurou-se, sem preocupação estatística, selecionar os trechos das entrevistas que permitiriam compreender como os trabalhadores constroem suas expectativas de futuro, o que implicou na utilização de parte do material coletado.

\section{Resultados}

\section{Contexto do estudo}

As formas de condução das atuais políticas públicas no País relativas à qualificação profissional e à inserção no mercado de trabalho vêm sendo pautadas em um sistema de racionalização das ações do Estado, que propõe redução de custos a partir de modelos calcados no setor privado. A operacionalização dessas políticas pelos três níveis de governo, para além das especificidades regionais incluindo-se aspectos políticos, culturais e econômicos -, tem revelado um quadro marcado pela fragmentação em sua implementação, por dificuldades na distribuição e pelo não atendimento às demandas sociais de usuários e trabalhadores.

Mais especificamente, no que se refere aos trabalhadores de nível técnico da saúde, a análise dos contextos regionais onde as entrevistas foram realizadas aponta que o trabalho no setor público não se configura de forma homogênea, quanto a vínculos de trabalho, remuneração, carga horária e estímulo à qualificação.

Quando se consideraram as relações de trabalho, verificou-se que a vinculação dos trabalhadores ao SUS se efetivou, 
principalmente, a partir de concurso público, seleção pública, terceirização e contratos temporários, situações que, no caso de alguns trabalhadores, podem inclusive se sobrepor. Cabe assinalar que essas diferentes formas de vinculação repercutem na remuneração e na carga horária semanal de trabalho contratada, que varia entre 30 e 40 horas. Quanto à remuneração, a variação se encontra entre 1 salário mínimo (SM) e 1,5 SM, podendo ser aumentada mediante benefícios e gratificações associados ao local de atuação do trabalhador e à sua produtividade. As entrevistas apontam, ainda, a extensão da jornada de trabalho e a busca pelo aumento de renda através de atividades remuneradas e exercidas paralelamente ao contrato de trabalho, tanto no próprio setor saúde como fora dele.

As informações obtidas sugerem que existem poucos estímulos à continuidade da formação-qualificação. No entanto, chama a atenção o fato de que os servidores graduados de Rio Branco (AC) recebem $20 \%$ a mais no vencimento básico, mesmo atuando como trabalhadores de nível médio. Além disso, vale ressaltar que o município de Blumenau (SC) concede auxílio financeiro aos servidores para a realização da primeira graduação, notando-se que a região é dotada de uma gama de cursos superiores, ainda que privados, o que facilita a continuidade dos estudos.

\section{Os entrevistados}

A origem social desses trabalhadores é relacionada a graus mais ou menos intensos de precariedade social. A maioria é do sexo feminino, encontra-se na faixa etária dos 30 aos 50 anos e ingressou em idade regulamentar em escolas públicas. Contudo, destes, uma parcela considerável interrompeu os estudos na transição para o ensino médio, a fim de ingressar no mercado de trabalho, quase sempre diante da necessidade de contribuir para aumentar a renda familiar, prover sua própria subsistência e/ou conquistar sua autonomia em relação à própria família.
O lapso de tempo decorrido até o retorno à escola é, não raro, extenso, e tende a ser maior para as mulheres, devido ao casamento e à maternidade. A retomada dos estudos se dá, com frequência, em instituições públicas que oferecem cursos noturnos, embora alguns entrevistados tenham dado continuidade à sua trajetória escolar no setor privado.

Quase todos são filhos de pais com baixa escolaridade e que transitaram por múltiplas ocupações, como domésticas, costureiras, doceiras, cabeleireiras, motoristas, pedreiros, trabalhadores rurais e extrativistas, nas regiões Sul e Norte. Em boa parte das vezes, essas atividades foram exercidas informalmente, cabendo chamar a atenção para um quantitativo importante de mães 'donas de casa'. No momento da entrevista, a maior parte deles residia em casas próprias, tendo sido encontrados também aqueles que moravam em casas cedidas por pais ou parentes, e casos de servidores que, já com família estabelecida (inclusive, filhos), alojaram-se nas casas de seus pais.

\section{Em busca de novas qualificações}

Nota-se que, para quase todos os trabalhadores entrevistados, independentemente da região estudada, gênero e faixa etária, a formação técnica não é mais suficiente. A obtenção de um diploma de nível superior é um anseio quase sempre associado à melhoria das condições de vida para si próprios e suas famílias. Mais da metade cursou, está cursando ou pretende cursar uma faculdade, com destaque para a enfermagem, seguida do serviço social. Outros, porém, revelaram a intenção de sair do setor saúde e tentar carreira em outras áreas, caso de Genivaldo, técnico de enfermagem, 34 anos, casado, que atua em Salvador (BA) e tem o sonho de estudar engenharia mecânica em uma universidade pública, para dar melhores condições de vida para a filha e se realizar profissionalmente.

A medicina aparece em vários depoimentos como uma aspiração difícil de ser 
concretizada, o que remete à origem social dos entrevistados. Por exemplo: Maísa tem 53 anos, é técnica de enfermagem em Salvador (BA); tentou enfermagem, acabou por fazer o curso de pedagogia, mas, quando criança, pretendia ser médica. Ela ressaltou que poderia ter ampliado ainda mais sua qualificação profissional, e tenta motivar os colegas mais jovens. "Eu tinha condição de ter chegado muito mais longe do que cheguei, mas deixei para trás. Eu falo com as minhas colegas: não parem" (Maísa, 53 anos, técnica de enfermagem - Salvador, Bahia).

Dênis, 32 anos, técnico de enfermagem de Campo Grande (MS), prepara-se para o Exame Nacional do Ensino Médio (Enem), a fim de ingressar na faculdade de enfermagem e, se possível, futuramente, no curso de medicina, que é o seu maior sonho:

[...] você vai se qualificando, vai ganhando meIhor, vai tendo mais condições. Então, quem começa, assim, lá do primeiro degrau, não pode ir ultrapassando. Então, vamos começar caminhando. E isso é bom, porque você conhece o que precisa, da raiz até se você chegar à medicina. (Dênis, 30 anos, técnico de enfermagem Campo Grande, Mato Grosso do Sul).

No mercado de trabalho em saúde, caracterizado pela capacidade de reter força de trabalho, a oferta de postos mais qualificados parece não acompanhar a velocidade de qualificação dos seus trabalhadores. Alguns poucos entrevistados frequentavam ou desejavam frequentar uma pós-graduação, que foi associada à maior possibilidade de aprovação em concursos públicos ou à docência de nível superior. A pós-graduação está, sobretudo, no horizonte dos técnicos em enfermagem, provavelmente porque são estes os profissionais entre os quais existe um maior número de graduados, tais como Julieta, de 41 anos, enfermeira e técnica de enfermagem no Rio de Janeiro (RJ). Ela relembra que, desde que começou a estudar, não pretendia trabalhar sempre como técnica de enfermagem: "Eu queria fazer faculdade". Quando da entrevista, cursava o mestrado com a perspectiva de ingressar na universidade como docente ou fazer doutorado.

Para outros, esse anseio está relacionado à possibilidade de continuar no setor saúde via uma inserção ocupacional melhor remunerada, menos desgastante e que proporcione maior autonomia e reconhecimento profissional e social. É o caso da Ana Lúcia, de 45 anos, ex-técnica de enfermagem do Rio de Janeiro (RJ), que, após a graduação em enfermagem, cursou a residência e fez especialização nessa área.

Quanto ao serviço social, destacam-se os casos dos Agentes Comunitários de Saúde (ACS), sobretudo daqueles entrevistados em Mato Grosso do Sul e Minas Gerais. É provável que essa preferência esteja relacionada com a proximidade entre o trabalho desempenhado pelo ACS e o do assistente social, conforme apontado por alguns dos entrevistados, como a ACS Lilian, 34 anos, de Minas Gerais, que, à noite, cursa o técnico em enfermagem e pretende fazer serviço social, pois considera que já está trabalhando nessa área, enquanto atua na saúde, lidando com a população. Paralelamente, Marluce (40 anos), Otília (26 anos) e Cristina (39 anos), que trabalham em Campo Grande (MS) como ACS, há mais de cinco anos (uma delas, há mais de 16), pretendem cursar serviço social e relacionam tal aspiração à possibilidade de ter mais autonomia para cuidar da população e atender às suas demandas. Note-se que Cristina, embora já aprovada, atualmente não dispõe de recursos financeiros para iniciar o curso.

Eliane, ACS do Rio de Janeiro (RJ), de 47 anos, gosta do trabalho que realiza, principalmente por "estar com o paciente quando consegue satisfazer as demandas". Quer ser feliz continuando a trabalhar como ACS e, se conseguir ingressar em uma faculdade, pretenderá cursar serviço social.

Uma alternativa é a psicologia. Notouse, ainda, que alguns trabalhadores pretendem dar prosseguimento à sua inserção 
no mercado de trabalho através de formação e exercício profissional em outras áreas de atuação, como direito, informática, engenharias e pedagogia. Este é o caso dos entrevistados da área da vigilância, que mencionaram o direito como possibilidade relevante para o exercício do trabalho na área, visto que favorece o entendimento da legislação e da gestão pública. Foi o que declarou Fabrizio, de 35 anos, que trancou o curso de fisioterapia, iniciado por indicação de amigos, por não gostar da área. Pretende continuar na vigilância, embora seu projeto de futuro seja alcançar uma boa pontuação no Enem, pois tem o sonho de cursar direito em uma universidade pública e prestar concurso para o cargo de promotor do Ministério Público (técnico em endemias - Salvador, Bahia). É de se notar, ainda, que parte dos entrevistados tem intenção de continuar a se qualificar para desempenhar as atividades associadas às suas atuais ocupações. Neste caso, a formação técnica em enfermagem se sobressai, já que constitui uma credencial que permite transitar pelos diferentes grupos estudados, considerando que esses postos de trabalho não exigem curso técnico específico.

\section{(Im)permanência na ocupação}

Chinelli, Vieira e Deluiz (2013) ressaltam que até o ingresso na saúde esses trabalhadores estavam inseridos em atividades as mais diversas, configurando trajetórias não lineares, o que vai ao encontro do que a literatura da área aponta para outros setores do mercado de trabalho (CASTRO, 2006). Ou seja, o desdobramento das trajetórias profissionais raramente é definido pelo primeiro emprego. Diante deste quadro, a inserção na área da saúde acaba significando, para quase todos os entrevistados, uma experiência de percurso mais estável, de estímulo à qualificação e de busca de vínculos mais protegidos, mais bem remunerados. No entanto, quando se trata de analisar as expectativas de futuro e, portanto, a relação desses trabalhadores com o grupo ocupacional estudado e com o próprio mercado de trabalho em saúde, verificam-se algumas diferenças no que se refere à permanência na ocupação.

Os ACS e os trabalhadores da enfermagem manifestam com mais recorrência a intenção de permanecerem em suas ocupações. A possibilidade de conciliar o trabalho com o cuidado da casa e dos filhos, e, ainda, o engajamento em outras atividades (sempre de caráter informal) são recorrentes entre os ACS. Estas atividades também são mencionadas pelos trabalhadores da enfermagem, neste caso, mais circunscritas a esta área de atuação, tais como múltiplos vínculos combinados entre formalidade e informalidade, setor público e privado, ocupação de postos de auxiliares, técnicos e enfermeiros. Além disto, parte dos ACS quer se manter na ocupação, pois encontra satisfação no trabalho, e este sentimento parece associado às alternativas que eles constroem no cotidiano laboral, de acentuada inserção local, com ênfase nos aspectos educativos e político-sindicais dessa atividade profissional. É isto que parece expressar um sentido, que ultrapassa os aspectos puramente instrumentais do trabalho.

A maior parte dos trabalhadores da enfermagem que possui vínculo como servidor público acaba permanecendo como técnico até a aposentadoria, mesmo que tenha concluído a graduação, já que a mudança para um cargo de nível superior exige aprovação em novo concurso público. Eles possuem vínculo mais estável do que os entrevistados de outros grupos ocupacionais estudados, o que justifica a ideia de aposentadoria na área para não perderem os direitos assegurados. Acrescente-se, ainda, o fato de que o campo profissional da enfermagem possui uma história mais longa, sendo mais definido seu processo de regulamentação profissional e educacional, o que permite a constituição de um grupo profissional com uma identidade mais nítida. Isto sugere, então, que estes trabalhadores têm possibilidades de delimitar, de forma mais clara, seus projetos profissionais, apresentando maior equilíbrio entre 
formação profissional e inserção ocupacional.

Mesmo assim, alguns desses trabalhadores manifestaram a intenção de sair da ocupação, ainda que, como no caso de Gisele, seguindo na área da saúde. Ela é técnica de enfermagem, tem 40 anos, atua em Campo Grande (MS) e pretende iniciar a faculdade de Recursos Humanos, pois acredita que lhe será útil no trabalho junto à Estratégia Saúde da Família (ESF). Este é o caso, também, de Sayonara, de 36 anos, que atua em Rio Branco (AC) e ingressou na enfermagem por influência da tia. Gosta da profissão, mas se sente desmotivada com o salário e as condições de trabalho. Pretende construir a casa própria e cursar a faculdade de direito.

As dificuldades que encontram em suas trajetórias informam suas expectativas de futuro, como já apontado. Antes de se inserirem na saúde, a ideia de construção de um projeto profissional associado à possibilidade de realização e crescimento era algo pouco provável, considerando o itinerário 'errático' construído antes desse ingresso na saúde. A partir daí, abriu-se, para os entrevistados, um campo de possibilidades, que pode ser considerado mais estável (VELHO, 2003) do que as inserções anteriores permitiam.

De forma geral, os entrevistados da vigilância em saúde foram mais enfáticos ao ressaltarem aspectos que remetem às especificidades desse campo, como as tensas relações hierárquicas, a não obrigatoriedade da formação técnica para atuação na área e a ausência do posto de trabalho de técnico em vigilância em saúde, constituindo-se este último no principal desmotivador da permanência na ocupação. A este aspecto pode ser acrescido o sentimento de desvalorização profissional e o fato de que o trabalho que desempenham não está, na maioria dos municípios, integrado a uma equipe, o que faz sentirem-se apartados, em um reduto próprio da vigilância. Fabiano, de 34 anos, com atuação no município do Rio de Janeiro (RJ), ingressou na área motivado pela estabilidade do vínculo como estatutário. Ele destaca problemas inerentes à sua ocupação, como o esforço físico decorrente do trabalho na rua e ao sol. Desde que ingressou na ocupação, vários de seus colegas abandonaram o vínculo, por razões que passam pelas características desgastantes da atividade, tipo de vínculo, remuneração e, ainda, por almejarem um cargo que reconheça a escolaridade de nível médio.

Todos os entrevistados dessa área, atuantes na capital do Acre, por exemplo, pretendem deixar a vigilância e percebem a conclusão da graduação como possibilidade de passagem para uma nova experiência profissional. Renata e Gabriel, ambos de 25 anos; Janis, de 37; Adriana, de 26; e Núbia, de 40, pretendem, através da educação física, da geografia, do serviço social, da pedagogia e da gestão pública, mudar de área e satisfazer suas expectativas profissionais.

Em Blumenau (SC), no entanto, três dos entrevistados estão se graduando para continuarem na área. Eduardo, 42 anos, trabalha na vigilância em saúde e exerce, também, a atividade docente. Desde seu ingresso no serviço público, frequentou todos os cursos de capacitação que a prefeitura ofereceu, obtendo, com isso, melhores posições no trabalho. Sua esposa, sabendo da paixão do marido por legislação e de sua resistência em ingressar na faculdade, inscreveu-o no vestibular para direito. Nas palavras dele:

Ela sabe da minha paixão pela legislação, por discutir as leis. [...] nós nunca tivemos um advogado na vigilância e eu reclamava em casa.

Seu maior sonho é tornar essa vigilância referência como a melhor do País, com salário digno e reconhecimento.

Eu quero fazer um mestrado na área da saúde para ser um professor melhor. [...] Eu gosto de dar aula, mesmo com a bagunça toda. Eu sou elétrico.

Jean tem 34 anos e é formado em sistemas da informação por uma faculdade comunitária de Blumenau (SC). Abandonou, por 
motivos pessoais e por sobrecarga de trabalho, um emprego bem remunerado, para trabalhar na área de vigilância. Iniciou como auxiliar de fiscalização contratado, com salário bem menor do que o que tinha antes. À época da entrevista, já era servidor público e atuava, também, como professor de administração, à noite, sem carteira assinada. Pretende continuar na vigilância e frequentar outro curso superior, para se aperfeiçoar mais nessa área:

O que eu queria mesmo era fazer engenharia sanitária, mas, por aqui não tem. [...] Eu não costumo fazer planos a longo prazo, gosto de fazer planos a curto prazo, emendando coisas a longo prazo. [...] Eu gosto de pegar e realmente colocar objetivos pequenos.

Josiane, de 35 anos, trabalhava na Câmara de Vereadores de Blumenau. Por intermédio de um político que conhecia seu interesse pela área da saúde, conseguiu se inserir na vigilância, em um momento em que havia necessidade de fiscais. Foi contratada por sete anos. Cursava pedagogia quando fez o curso técnico de vigilância e prestou concurso para a prefeitura. Quando da entrevista, cursava biomedicina, pois, na área em que atua, deve estar sempre se aperfeiçoando:

[...] as coisas vão mudando, as legislações vão mudando, quanto mais conhecimento tiver, mais à frente tu vai estar. A gente não pode ser fiscal de piso e parede, tem que ser fiscal de um tudo.

Pretende continuar trabalhando na vigilância, tentando conciliá-la com a biomedicina. Conforme afirmou,

[...] dá para conciliar, de repente, dois vínculos [...]. Então, é por isso que eu acho que, depois de me formar, não sei o que possa acontecer até lá. [...] eu estou sempre em busca de aprender e de crescer. De repente, amanhã, eu vá trabalhar numa empresa privada, a gente não sabe [...].

A área de saúde bucal parece ser a que menos consegue reter os trabalhadores, que sinalizam insatisfações relacionadas ao fato de permanecerem, de forma geral, restritos aos procedimentos indicados pelo dentista, e submetidos às dificuldades de realização profissional, à fragmentação e à não integração em equipes de trabalho. Sueli tem 43 anos, começou a trabalhar ainda criança, vendendo mandiocas que sua mãe plantava. Trabalhou também como babá, empregada doméstica e vendedora (em loja e em sorveteria), até ser aprovada em concursos públicos: auxiliar administrativo, auxiliar social e técnico em saúde bucal. Afirma que gosta do que faz, mas está desiludida com a atividade na saúde bucal, pelas condições de trabalho, baixa remuneração, falta de reconhecimento profissional e porque entende que sua atuação se resume a informar e encaminhar:

Ah, o desencanto é porque, primeiro, a profissão não é reconhecida; segundo, que você não tem uma cadeira para você trabalhar. Então, a única coisa que eu posso fazer do meu serviço é informar, a atenção básica.

É formada em letras e em serviço social porque gosta de trabalhar com pessoas. Seus planos incluem outros concursos públicos, para trabalhar como assistente social.

Bete tem 57 anos e atua como técnica em higiene dental, em Campo Grande (MS). O interesse pela área da saúde surgiu ao precisar cuidar do pai. Fez um cursou de auxiliar de enfermagem e, posteriormente, prestou concurso para técnico em higiene dental. Afirma que migrou da enfermagem para a saúde bucal porque, à época, compensava financeiramente, mas hoje considera que teve prejuízo. Gosta muito do que faz e não se arrepende de ter mudado, mas sente que sua profissão não é valorizada, do ponto de vista salarial e das condições de trabalho, e pensa na possibilidade de voltar para a enfermagem.

Solange, 34 anos, é auxiliar de saúde bucal em Belo Horizonte (MG), dá aulas de percussão e, nos finais de semana, canta com o 
marido. Não pensa em continuar trabalhando na área, pois não gosta do que faz, sente-se mal ao ver sangue. Avalia a possibilidade de frequentar um curso na área de enfermagem ou de cuidador, apenas por uma questão pessoal, porque seus pais estão ficando idosos e quer cuidar deles. No futuro, pretende trabalhar apenas com música, já que toca com o marido, o sogro e o pai. É o que gosta de fazer e o que a está proporcionando a melhor renda.

Já Juliana, de 28 anos, é policial militar (PM) em Belo Horizonte (MG) e pretende continuar trabalhando na polícia militar, no setor da saúde bucal. "Gosto de auxiliar, ver o que está sendo feito, começar o tratamento, vê-lo terminar e ver que a pessoa está satisfeita". Cursa a faculdade de direito à noite. "Direito é para planejar seu futuro".

Ecivalda, técnica de saúde bucal em Salvador (BA), tinha como aspiração fazer odontologia:

Porque sou técnica de odontologia e me apaixonei. Mas, a realidade de fazer odontologia é outra, não era a minha. É um curso caro, muito material. Eu tive que esquecer esse sonho e partir para uma outra área.

Acabou cursando serviço social, pretende fazer pós-graduação, mestrado, doutorado e passar em um concurso de nível superior.

\section{Em outra etapa da vida, é possível recomecar}

Os entrevistados, sobretudo os que se encontram mais próximos do encerramento do ciclo da vida profissional, têm como perspectiva a aposentadoria na área em que trabalham, ou fora dela. Isto não significa, necessariamente, que pretendem parar de trabalhar. Para muitos, uma nova inserção no mercado de trabalho possibilitaria um acréscimo de renda e/ou a oportunidade de perseguir novos projetos profissionais e/ou alguns daqueles que foram deixados para trás. Não raramente também mencionaram o desejo de 'curtir' a vida, os netos, a casa, o jardim, iniciar a viagem sonhada, entre outros. Para eles, é outra etapa da vida que se inicia, conforme frisou José Bento, de 60 anos, técnico em saúde bucal. Sua filosofia de vida é pensar que "na vida, nada termina, tudo começa".

André, técnico de enfermagem, 50 anos, é servidor estadual no Rio de Janeiro (RJ) há 22 anos. Desde 2005, possui um segundo vínculo, como contratado na Fiocruz. Tem a expectativa de se aposentar e não parar de trabalhar. Quer aumentar sua renda como paisagista, pois gosta muito de plantas, tendo feito, para tanto, um curso de jardinagem. Também a já mencionada Bete, de 57 anos, que atua na saúde bucal de Campo Grande (MS), sinaliza que está quase se aposentando e depois não deseja mais trabalhar, apenas viajar. Pérola, de 58 anos, técnica de enfermagem no Acre, pretende continuar trabalhando gratuitamente depois de se aposentar.

Um vizinho meu, fazendeiro, fala que daqui a um tempo quer montar uma clínica de repouso para idosos. Eu disse a ele que, mesmo depois de me aposentar, enquanto puder trabalhar, gostaria de tirar três, cinco plantões por semana, gratuitamente, só para ter o prazer de estar cuidando.

Luis Carlos é ACS em Blumenau (SC), tem 55 anos, e gostaria de atuar na área de psicanálise, trabalhando com adolescentes. Já atende "[...] alguns grupos de adolescentes na quarta-feira à noite em uma instituição, em parceria com o município, junto com os professores". Já o depoimento do Genivaldo até destaca a intenção de saída da ocupação, mas visa a um retorno após a aposentadoria, tendo manifestado interesse em cursar engenharia mecânica e "prestar concurso para qualquer outra área, pois considera trabalhar na saúde pesado e desumano". No entanto, quando se aposentar, tem a intenção de retornar à enfermagem, para prestar serviços voluntários para crianças e idosos. Teresinha, que reside em Blumenau (SC), pretende continuar trabalhando como técnica de enfermagem "até 
o hospital achar que não tem mais condições de trabalhar". Ela tem 54 anos e, depois de trabalhar mais alguns anos, quer aprender a fazer trabalhos manuais: "Como eu gosto e sei fazer alguma coisa, quero me aprofundar mais em trabalho manual, artesanato".

\section{Considerações finais}

A análise das expectativas de futuro dos entrevistados revela que o ingresso na saúde redireciona suas erráticas trajetórias anteriores. A partir daí, as dificuldades e incertezas experimentadas no início da vida profissional se atenuam, mas não desaparecem completamente. Tanto é assim que a maioria dos entrevistados pretende permanecer na área da saúde, na mesma ocupação ou em outra, quase sempre projetada de forma ascendente, para uma profissão mais bem remunerada e socialmente mais valorizada. Por isto mesmo, cabe sugerir que suas aspirações podem se transformar em expectativas, tornando-se mais viável a construção de projetos de vida. De fato, a partir das entrevistas, foi possível constatar que a área da saúde se apresenta como um setor do mercado de trabalho brasileiro em que o emprego é vivenciado como mais estável, quando comparado aos demais setores, sobretudo para aqueles trabalhadores menos qualificados e que experimentaram trajetórias anteriores marcadas pela incerteza advinda de inserções instáveis e precárias. Não se quer dizer, com isto, que o mercado de trabalho em saúde esteja imune aos problemas vividos pela maioria dos trabalhadores do País. $\mathrm{Na}$ verdade, em comparação aos cursos de vida anteriores ao ingresso no setor, trata-se de, ao menos, obter, mesmo que por tempo limitado, os direitos já flexibilizados, garantidos pela legislação específica. Embora estejam, de forma crescente, submetidos a contratos terceirizados (tendência de boa parte dos municípios brasileiros), baixos salários e ritmos intensos de trabalho impostos pela necessidade de atingir metas estabelecidas, os trabalhadores técnicos sentem-se menos vulneráveis, até porque encontram oportunidades - não necessariamente distribuídas de forma equitativa - de obter mais qualificação e, portanto, tentar atingir um posto de trabalho mais reconhecido e mais bem remunerado, mesmo após a aposentadoria.

A análise dos depoimentos permitiu constatar que a inserção na saúde possibilitou elaborar projeções para o futuro que expressam suas trajetórias anteriores. Com isto, considera-se que o estudo das trajetórias educacionais e ocupacionais se confirma como temática relevante no campo do trabalho e da educação, merecendo a ampliação de análises que tratem do tema deste artigo, no âmbito da saúde.

\section{Colaboradores}

Monica Vieira e Filippina Chinelli participaram de todas as etapas da elaboração do artigo: concepção, planejamento, levantamento, análise, interpretação dos dados e redação. Os demais autores participaram do levantamento e interpretação dos dados, e da revisão final do texto.

\section{Agradecimentos}
Agradecemos ao Programa de Apoio à Pesquisa Estratégica em Saúde (Papes)/Fiocruz/Conselho Nacional de Desenvolvimento Científico e Tecnológico $(\mathrm{CNPq})$ e aos pesquisadores do estudo, es- pecialmente aos colaboradores deste artigo: Arthur de Andrade Fontenelle, Joelma Pinheiro Meira Barbosa, Arlinda B. Moreno, Ana Margarida de Mello Barreto Campello e Francisco José da Silveira Lobo Neto. 


\section{Referências}

ALVES, G. A Condição de proletariedade na modernidade salarial - por uma analítica existencial do proletariado. Revista Pegada, Presidente Prudente, v. 9 n. 21, dez. 2008. Disponível em: <http://revista.fct.unesp.br/ index.php/pegada/article/view/1672>. Acesso em: 5 jul. 2016.

CASTRO, N. Trajetórias Inseguras, autonomização incerta: os jovens e o trabalho em mercados sob intensa transição ocupacional In: CAMARANO, A. A. (Org.). Transição para a vida adulta ou vida adulta em transição. Rio de Janeiro: IPEA, 2006.

CHINELLI, F.; VIEIRA, M.; DELUIZ, N. O Conceito de Qualificação e a Formação para o trabalho em saúde. In: MOROSINI, M. V. G. C. et al. (Org.). Trabalhadores técnicos em saúde: aspectos da qualificação profissional no SUS. 1. ed. Rio de Janeiro: EPSJV/Fiocruz, 2013, p. 23-48.

FRANCISCO, D. S. Gestão do Trabalho e Valorização Profissional: a questão da sobrequalificação para o trabalhador técnico do SUS. 2015. 89 f. Dissertação (Mestrado Profissional em Educação Profissional em Saúde) - Escola Politécnica de Saúde Joaquim Venâncio, Fundação Oswaldo Cruz, Rio de Janeiro, 2015.

LAHIRE, B. A cultura dos indivíduos. Porto Alegre: Artmed, 2006

MINAYO, M. C. S. O desafio do conhecimento: pesquisa qualitativa em saúde. 9. ed. São Paulo: Hucitec, 2004.

NOGUEIRA, C. Escolha Racional ou Disposições Incorporadas: diferentes referenciais teóricos na análise sociológica do processo de escolha dos estudos superiores. Estudos de Sociologia, Recife, v. 2, n. 18, 2012. Disponível em: <http://www.revista.ufpe.br/revsocio/index.php/revista/article/view/66/52>. Acesso em: 1 abr. 2016.

SAVIANI, D. Perspectiva Marxiana do problema subjetividade-intersubjetividade. In: DUARTE, M. (Org.). Crítica ao Fetichismo da individualidade. São Paulo: Autores Associados, 2004.

SCHUTZ, A. The problem of social reality. Holanda: Springer Netherland, 1979.

SILVA, L. F. C. Percursos Desiguais. Trajetórias ocupacionais dos trabalhadores no setor de telecomunicações no período pós-privatização. 2011. 241 f. Tese (Doutorado em Sociologia) - Universidade Federal do Rio Grande do Sul, Porto Alegre, 2011. Disponível em: <https://www.lume.ufrgs.br/bitstream/handle/10183/29397/000776364.pdf?sequence=1>. Acesso em: 1 abr. 2016.

VELHO, G. Projeto e Metamorfose: antropologia das sociedades complexas. Rio de Janeiro: Jorge Zahar, 2003.

VIEIRA, M. et al. Formação Técnica e da Ocupação de postos de Trabalho em Saúde - Brasil, anos 2000. In: MOROSINI, M. V. G. C. et al. (Org.). Trabalhadores técnicos em saúde: aspectos da qualificação profissional no SUS. 1. ed. Rio de Janeiro: EPSJV/Fiocruz, 2013. p. 121-148.

Recebido para publicação em agosto de 2016

Versão final em janeiro de 2017

Conflito de interesses: inexistente

Suporte financeiro: Programa Papes - Fiocruz/CNPq: Processo 407733/2012-4 